\title{
1. Contextualising donor conception and anonymity
}

DI as the oldest form of treatment with donated gametes is technically easy to perform. Its basic principles have not changed over the past decades. Sperm from a man who is not the patient's partner is produced by masturbation and is then transferred into the patient's uterus or vagina. Ideally, pregnancy occurs, and after nine months a child that, in the case of a heterosexual couple, is not genetically related to the man who is raising the child, is born. As simple as the process itself is, it has always fascinated, irritated and often horrified people. The same is true for technologically more complicated methods that might include the use of donated gametes: a long-cherished wish for a child and for the experience of parenthood may be fulfilled, which tends to be celebrated. At the same time, the use of donated gametes in particular causes discomfort, as it challenges established ideas about family, conception, and reproduction. While the practice of anonymising donors and keeping the donation a secret has often been seen as the solution to these challenges, today anonymity as well as secrecy are increasingly being criticised for being harmful for both children and families.

Before discussing my own empirical material in chapters 3-8, I will first present developments, debates and discourses that are relevant to my research. Thus, the following four sections serve to contextualise my own analysis. It should be noted that I do not conceive of "context" as something out there to be found. Instead, contexts are "sets of connections construed as relevant to someone, to something or to a particular problem" (Dilley 2002: 454). Trying to establish "a claim about context" (ibid.) will thus always remain a claim that is "socially and historically situated" (ibid.), and contexts remain "expandable" (ibid.). According to anthropologist Roy Dilley, "the best we can do is to look to the relations between knowledge, context and power that seem to fix some meanings and interpretations rather than others as pre-dominant or even hegemonic forms" (ibid.). As I will show in this chapter, a certain way of contextualising and interpreting anonymous gamete donations as a threat to identity has established itself as a dominant perspective. Thus, this chapter is not only designed to provide relevant background knowledge that helps to situate my material but is also a "context claim" that represents my attempt to 
open up other approaches to the topic, namely by drawing on anthropological approaches to anonymity, donor conception, openness and disclosure.

I will first give an overview of how the regulation of reproductive technologies and donor conception has developed in the UK and Germany. Despite certain differences, it will become clear that in both countries the answer to the question of what kind of information the donor-conceived can obtain is not uniform. I will then discuss how anonymity and donor conception are situated in psychosocial research, which has produced a lot more studies on donor-conceived people than anthropology. In this section, I will discuss the empirical gaps that my ethnographic research fills and how my anthropological approach to anonymity in gamete donation differs from the focus on "identity formation" that dominates psychosocial studies. Subsequently, I will examine how anonymity has been ethnographically investigated to date, and what the particular strength of my material is in terms of ethnographically exploring anonymity. In the last part of this chapter I will focus on some of the anthropological research on kinship knowledge, donor conception and disclosure that has shaped my own approach to the topic. While throughout this book I will repeatedly refer to different ethnographies on these and other topics, in this section I will discuss in condensed form the concepts and theories that have been particularly pertinent to my own analysis.

\subsection{Regulating donor conception}

Inseminations with donor sperm had been carried out in both the UK and Germany long before the development of In-Vitro Fertilisation (IVF) (for early medical reports on DI, see Barton et al. 1945; Schaad 1972; Rose and Schaad 1974), and anonymity in donor conception had already been the subject of legal and ethical debates as early as the 1940s (Haimes 1998). However, reproductive technologies in general started to receive a lot more public as well as political attention following the birth of Louise Brown, the first person to be conceived via IVF. ${ }^{1}$ While DI in itself does not create a completely new situation, as there have always been children who did not grow up with their genitor, IVF created something unprecedented: fertilisation outside the body. This made it necessary to find an appropriate way of dealing with extracorporeal embryos and egg cells. It should be noted that most of the people I interviewed were not conceived through IVF, but through DI. In fact, of those who were conceived at a time when IVF was already available to patients, only one

$1 \quad$ IVF involves the surgical extraction of oocytes, which are monitored and fertilised in a laboratory. The resulting embryos are then transferred into the patient's uterus. 
person stated that he was conceived through such treatment. I had not asked my interviewees about it, but he mentioned it on his own initiative. ${ }^{2}$

However, in both the UK and Germany the debates about the "unprecedented procreative possibilities" (Richardt 2003: 87) created though IVF also included discussions about the much older practice of DI and the anonymity of donors that was by then the clinical norm. While the British debates resulted in the establishment of a central donor register and strict regulation on embryo research, this was not the case in Germany. Embryo research remained prohibited and no such register was created. The debates on IVF thus had an influence on how information on donors was managed, which in turn had an effect on the way the donor-conceived can proceed in their search for information. I will discuss these debates briefly, focusing on how anonymity was debated by two specific commissions of inquiry that were set up in response to the development of IVF and the legal developments that followed, or did not follow, their recommendations. Furthermore, I will give an overview of the current situation with regard to access to donor information, before going into more detail in chapter 3 on how demands for a right to know influenced important changes in this domain. I will return to the topic of IVF in chapter 8 where I discuss commercial genetic testing and the phenomena of "having to try" DNA testing and "waiting for matches", drawing on ethnographies of assisted conception (Franklin 1997; Throsby 2004).

The new procreative possibilities include in particular the donation of oocytes and the implantation of an embryo that was not created with an oocyte from the woman gestating the foetus, which means that the "organic unity of the fetus and the mother can no longer be assumed" (Martin 1989: 20). Prior to IVF, it was only fatherhood that was thought to be intrinsically uncertain (Strathern 1992: 148). With IVF, motherhood was no longer certain either. Besides, 'surplus' embryos that were not used in an IVF cycle could be used in embryological research, and embryos could be created specifically for that purpose (Richardt 2003: 87). In addition, the further development of cryopreservation methods made it increasingly possible to store and transport gametes and embryos. It became necessary to find a way of dealing with these new cryopreserved entities. ${ }^{3}$

Only Jacob Moore from the UK, who was conceived with a donor egg and who had always known about the circumstances of his conception, mentioned that he was conceived via IVF, which is arguably not surprising given the differences between treatment involving donor sperm and donor ova. In the case of egg donation, the donated egg cells are fertilised in a Petri dish and then transferred into the recipient's uterus, whereas treatment with donor sperm does not have to involve IVF. In fact, it was Jacob's interest in IVF that sparked his interest in his genetic half-siblings and in his anonymous donor (see section 7.5).

3 Those of my interviewees who had been conceived in the 1970s to mid-1980s usually told me that, according to the information given to their parents, they had been conceived with 'fresh', unfrozen sperm. In the case of unfrozen semen, the donation was often made shortly 
The first birth resulting from an IVF treatment "was seen to create not only a new kind of reproductive choice but a legal vacuum surrounding its use, as well as an immediate practical imperative to produce regulation" (Franklin and Roberts 2006: 40). In the UK, the government reacted to these challenges by setting up a committee of inquiry in 1982, 14 years after DI had become available on the National Health Service (NHS) (Frith 2001: 820). When the inquiry was set up, anonymity and secrecy had already dominated the much-criticised practice for several decades. ${ }^{4}$ The committee was led by philosopher Mary Warnock and laid the foundation for what has been described as "the world's most comprehensive legislation on human reproduction and embryology" (Franklin and Roberts 2006: 41). The so-called "Warnock Committee", which published its report in 1984, managed to "establish[...] a pattern that has prevailed ever since in Britain" (Franklin and Roberts 2006: 3) regarding the regulation of reproductive and genetic technologies, namely to "achieve workable and sustainable policy" (Franklin and Roberts 2006: 5 , emphasis in original). ${ }^{5}$

The Warnock Committee endorsed the practice of gamete donation and recommended that a child conceived with donated gametes "should in law be treated as

before the insemination took place. Patients and donors were likely to be in close physical proximity of each other at some point. A German gynaecologist told me that in his practice, they sometimes ran into each other on the stairs. To avoid this, he started working with cryopreserved sperm in the 1980 .

4 In response to "a growing public and professional debate" (Richards 2016: 15) that followed early medical reports on donor conception in the UK, the Archbishop of Canterbury had already commissioned a report on DI in 1946. The report, which was published in 1948, argued that the method should be banned by law (Daniels and Taylor 1993: 156). DI was rejected for religious and moral reasons: masturbation, as a way of obtaining sperm, was considered a sin. Both secrecy and disclosure were seen as harmful (Haimes 1998: 57). Although DI was subsequently not banned by the government, "negative attitudes [...] made the practice rather more secretive and under the counter during the late 1940s and 1950s" (Richards 2016: 16). The Peel Committee came to a different conclusion (Peel Report 1973). It had been set up by the British Medical Association to examine matters of artificial insemination and accepted DI "as appropriate medical practice" (Richards 2016: 23). While there was no mention of whether a child should be told or not, the authors of the report seemed to take the importance of anonymity for granted: "In order to preserve anonymity it would be necessary for information about donors sent by the frozen-semen banks to accredited centres or to private practitioners to be in coded form [...]." (Peel Report 1973: 5)

5 The Committee not only discussed the views of its members but also considered evidence submitted or presented by organisations working in the field of human reproduction, as well as by individuals such as adoption researchers. Apart from this evidence, it also received almost 700 submissions from the public (Warnock Committee 1984: 95; see also the introduction of chapter 4, where I mention a submission made by a donor-conceived person). However, it is unclear how this evidence, which was never published, shaped the final recommendations (Cavaliere 2017: 3). 
the legitimate child of its mother and her husband" (1984: 23-24, emphasis in original). By contrast, an "AID child", as it is referred to in the report (with AID standing for "Artificial Insemination by Donor"), was previously regarded as illegitimate. Although the husband was registered as the father, this was officially considered an offence, and "the problems with legal paternity contributed to the desire to keep the practice secret" (Frith 2001: 820).

At that time, the anonymity of the donor had a protective function, as it prevented the donor from being forced to assume parental responsibilities and the husband from being displaced as the legal parent (ibid.). The Warnock Committee also believed that anonymity would protect several other vital interests: not only would it give "legal protection to the donor, but it would also have the effect of minimising the invasion of the third party into the family" (1984:25). At the same time, the Committee argued "that it is wrong to deceive children about their origins" (1984: 21) and that secrets were harmful to family relationships (ibid.). Nevertheless, it suggested that parents should only be given limited information about the donor. Only "basic facts [...] such as his ethnic group and his genetic health" (1984: 24) were to be recorded and be given to recipients. Members of the Committee did not want "to encourage parents to seek donors with specific characteristics in the hope of producing a particular type of child" (Richards 2016: 29). Additionally, the Committee recommended for such "basic" information to be made available to the child at the age of 18 and stored in a central register (1984: 82).

The Human Fertilisation and Embryology Act (HFE Act) from 1990 largely followed the recommendations of the Warnock Report. ${ }^{6}$ Apart from donor conception, it also regulates fertility treatment that does not involve donated games, research on embryos, ${ }^{7}$ as well as storage of gametes and embryos. The HFE Act provided for the establishment of the Human Fertilisation and Embryology Authority (HFEA), an executive, non-departmental public body that began its work on 1 August $1991 .^{8}$ The HFEA primarily functions as a licensing authority that oversees all centres and clinics that collect, store and use human gametes and embryos

6 A voluntary regulatory body called Interim Licensing Authority (previously Voluntary Licensing Authority) had been established in 1985 by the Medical Research Council and the Royal Society of Obstetricians and Gynaecologists. However, it did not cover treatment with donated games unless it involved IVF or gamete intra-fallopian transfer (Blyth 2004: 227), a procedure that involves placing eggs and sperm in one of the Fallopian tubes. The Interim Licensing Authority remained active until the HFEA was established.

7 Research on embryos is limited to a maximum period of 14 days after their creation.

8 From now on I will only use 1991 in this book instead of the full date when referring to the date which divides the donor-conceived into two groups in terms of what they can find out about their donor. The same applies to 1 April 2005, the date from which donor anonymity was limited in time. When I refer to the period between 1991 and 2005, I mean, strictly speaking, the period between 1 August 1991 and 31 March 2005. 
(Franklin and Roberts 2006: 61). From the very beginning it also had the task of keeping a register with information on all donors and treatments involving donated gametes. The HFE Act permitted "the government to issue regulations authorizing the disclosure of [...] information relating to the donor to an individual who was conceived following donor treatment and who has reached the age of 18 " (Blyth 2004: 235). However, it did not include regulations concerning the release of information (ibid.). Although sperm donation had already been practised for several decades at this point, it was not until the HFE Act came into effect that gamete donation was legitimised in the UK. The Act provided that in the case of DI, the mother's husband or partner would be registered as the legal father, while the donor remained anonymous. The legitimisation thus occurred under conditions that upheld the ideal of the nuclear and heteronormative two-parent-family. In this sense, anonymity can be described as a mechanism that "helps to preserve as many as possible of the conventional features of the family by setting a barrier around the unit" (Haimes 1990: 169). ${ }^{9}$

Following extensive campaigning by a working group within the British Association of Social Workers (BASW) that had been formed in the wake of the Warnock Report (Wincott and Crawshaw 2006), a government consultation (section 3.4), and a court case that involved a donor-conceived adult and a donor-conceived child (section 3.2), the law was eventually amended in 2004 . The change was announced "on the basis that a child's right to learn its genetic inheritance out-weighed the donor's right to privacy" (Thomson 2008: 114). The 2002 court case in particular will be discussed in more detail in section 3.2 when I explore and analyse one of the most omnipresent topics of my research, namely the right to know. With effect from 1 April 2005, persons conceived after that date have the possibility to obtain identifying information (name, date of birth, last known address) about their

The extent to which the HFE Act can be interpreted "as a strong moral statement of the importance of the nuclear family" (Sheldon 2005: 527) is particularly evident in the "need for a father clause". The 1990 Act (section 13(5)) stated that "a woman shall not be provided with treatment services unless account has been taken of the welfare of the child who may be born as a result of the treatment (including the need of that child for a father)". While the Act did not explicitly state that single women and lesbian couples should not have access to treatment, this provision gave clinics a basis for refusing them treatment. The Act was updated in 2008, and "need for a father" was replaced with "need for supportive parenting" (see also Blyth 2015 for a more detailed discussion of this development). Female partners are now registered as legal parents, alongside the gestating mother. Although these changes might seem revolutionary at first, a traditional "two parent model retains a grip on the law" (McCandless and Sheldon 2010a: 191). The law still adheres to the view that it is best for children to be raised by two parents that are in a sexual relationship; "what changes is the necessity that one of the two must be a father" (McCandless and Sheldon 2010b: 209). 
donor from the age of 18. In addition, they can obtain non-identifying information (such as physical description, year and country of birth, ethnicity, whether a donor had children at the time of donation, marital status) from the age of $16 .{ }^{10} \mathrm{At}$ that age they can also receive basic information about their donor siblings (number of children, year of birth, gender). Parents are given access to non-identifying information about the donor and any children conceived with gametes from the same donor. In UK policy documents, the importance of this information is framed "as significant to recipients in their role as parents (or potential parents) of donor-conceived children and not as directly meaningful to themselves" (Gilman and Nordqvist 2018: 324). Whereas provision of information to parents is not a statutory requirement, donors do have a statutory right to obtain non-identifying information about any children born from their donation but may never receive identifying information. It has been argued that disclosure of information to donors is "framed as means of ensuring that openness about donors is successful and that any implied disruption it might cause to their families is minimized" (Gilman and Nordqvist 2018: 326, emphasis in original). Openness is thus organised in very specific ways in UK policy, and priority is given to "information sharing about donors with their donor-conceived offspring" (Gilman and Nordqvist 2018: 318).

The HFEA also manages a voluntary sibling register that was set up in 2008 (Blyth and Frith 2015: 142). It enables those who join it to make contact with their donor siblings. Besides, those who donated after 1991, but before 2005 can choose to re-register with the HFEA and make themselves identifiable to any offspring who request information; otherwise, those conceived during that time can only obtain non-identifying information. They can also join the voluntary sibling register at the age of 18. Furthermore, those who were conceived or who donated before the establishment of the HFEA can join the voluntary Donor Conceived Register (DCR). It receives its funding from the Department of Health and facilitates DNA "linking" or "matching" between donor-conceived adults and donors, as well as between donor siblings (who are not eligible to join the voluntary HFEA sibling register). These different registers will be discussed in detail in chapter 7 .

In Germany, the debates on IVF, the regulation of reproductive technologies and donor anonymity took a very different course. When IVF was developed, anonymous and secret donations were the clinical norm, albeit not being mandated by law. In 1970, the Ärztetag, the annual meeting of the German Medical Association, declared DI to be a practice that was not in violation of the professional code of physicians (Bundesärztekammer 1970), thus overturning its 1959

10 Initially, the minimum age for accessing non-identifying information was 18 (Blyth et al. 2009: 209). 
decision. ${ }^{11}$ Prior to 1970 , physicians who performed the treatment risked losing their medical license, even though DI was not illegal. ${ }^{12}$ However, the 1970 Ärztetag also declared that it did not recommend the practice as such, as it was still fraught with too many legal problems, such as the issue of maintenance claims. Although DI was liberalised to a certain extent after 1970, anonymity and secrecy therefore remained dominant. In 1984, two years after the first German 'IVF baby' was born, the Federal Ministries of Justice and of Research and Technology appointed a committee of inquiry chaired by former Constitutional Court president Ernst Benda. With regard to donor anonymity, the recommendations issued by the so-called "Benda Commission" ("Benda-Kommission" in German) differed from the Warnock Report. It was considered wrong for sperm donors to remain anonymous: "Knowledge of one's own origins is of considerable importance for establishing identity and thus for personality development." (Benda-Kommission 1985: 14, author translation) The Benda Commission recommended that the law should be amended to require that the donor's personal details be documented and presented to the child on request from the age of 16 . However, its recommendations were not translated into law. In contrast to the UK, where information on donors was stored in a central register managed by the authority that also regulates embryo research, no such infrastructure was established in Germany. ${ }^{13}$ I suggest this has to do with the fact that the German debates on embryo research were very different from those in the UK.

In her comparative analysis of the embryological research debate in the UK and Germany, Nicole Richardt argues that permitting "even a limited amount of embryological research was perceived as entering onto a slippery slope that might lead to a population policy like that of Nazi Germany" (2003: 110), with all political

Due to legal uncertainties, Cerman university clinics discontinued their DI programs in 1984 (Katzorke 2008: 17). Little is known about how DI was organised and regulated in the former German Democratic Republic (GDR). According to publications from the 1980 (Graf and Clander 1980; Cünther 1987), donors were supposed to remain anonymous, and information on DI was documented in a central register. Those of my interviewees who had been conceived in the GDR pointed out that, to their regret, the whereabouts of this register are unknown.

12 In 1959, the Ärztetag had decided that inseminations with donor sperm were to be rejected on moral grounds and constituted a violation of the code of medical ethics (Katzorke 2008: 17).

13 Information about IVF treatments is stored in the Cerman IVF register, which was created in 1982. However, information on the use of donor semen is not recorded in it. In contrast to the Cerman donor register, its status remains uncertain (Kadi and Wiesing 2016: 682). While it was initially designed as "a voluntary association between IVF centers" (ibid.), the IVF register was later on recognised by the professional guidelines of the German Medical Association. However, it is currently lacking this kind of formal recognition and clinics are not required to submit data. 
parties opposing Preimplantation Genetic Diagnosis (PGD) as well (ibid.). It is interesting to note that the Benda Commission had in fact "allowed for the possibility of high-priority research on embryos" (Jasanoff 2007: 162). While the Benda Report made clear recommendations on embryo research, what followed was not consensus but "years of conflict" (Herrmann 2009: 131) between government officials at the federal and state level, medical professionals and public actors (ibid.). In parliamentary debates and expert commissions, discussions focused primarily on the question of whether embryos inside and outside the body should be given the same level of protection as humans that were already born (Knecht and Liebsch 2019: 103). By contrast, in the UK research on embryos was framed "in terms of progress rather than opening Pandora's box" (Richardt 2003: 108). In the end, conservative forces won in Germany. The Embryo Protection Act (Embryonenschutzgesetz; ESchG 1990) that was passed in 1990 did prohibit all forms of embryological research and PGD. Egg donation continues to be prohibited under the Act, resulting in Germans travelling abroad for treatment with donated ova (Bergmann 2014). The discursive creation of the pre-embryo that was not yet a proper embryo in the UK, "together with a less traumatic eugenics experience than Germany's" (Richardt 2003: 106) resulted in a UK law on embryological research that was "diametrically opposed" (Richardt 2003: 88) to the German regulation. While Warnock pursued "a strategy that is based not on absolute values of right and wrong but on the "bottom line" of deliberation within an established legislative system" (Franklin and Roberts 2006: 3), the German debate still seems to be more geared towards finding limits that are reflective of what is right and wrong in an absolute sense.

In the absence of a register and comprehensive regulation of DI, the decision as to what kind of information on donors was collected, how it was stored, and to whom it was made available, continued to be largely taken by the medical profession. German physicians in particular remained "gatekeepers" (Bateman Novaes 1998: 106) to a greater extent than their British colleagues, especially with regard to access to donor information. Anonymity was still the clinical norm. With the implementation of the European Union Tissue Directive (ETD) into German law within the Tissue Law (Gewebegesetz; GewebeG 2007) and through the Transplantation Act (Transplantationsgesetz; TPG 2007), the power that physicians exerted over information was only somewhat curtailed in 2007. While the law generally provided for anonymity, sperm donation was treated as an exception. The Transplantation Act stated that in the case of sperm donation, "the right of the child to know its own origins" (TPG 1997 \$14 (3), author translation) had to prevail. However, it was still not regulated how and at what time information should be made available. Some 
clinics began to store donor information with a notary so that children would be able to access it later in life. ${ }^{14}$

Following the implementation of the ETD, doctors were obliged to keep clinical records including donor information for at least 30 years. Previously, these documents had been destroyed in many clinics after ten years, with donor-conceived activists arguing that physicians should have ensured a longer storage period already prior to that (Spenderkinder 2016d). ${ }^{15}$ The extension of the mandatory storage period made it possible, at least theoretically, for adult donor-conceived persons to obtain information about their donor. While in some clinics the new regulation was only applied to treatments that took place after 2007 , in other treatment centres records that were already ten years old at that time were also kept. For this reason, some clinics and sperm banks state that they no longer have records for treatments that took place before $1997 .{ }^{16}$ Even for treatments that took place after 2007 , it is not always easy to obtain information about a donor, as the release of information was not clearly regulated. ${ }^{17}$ Overall, the Tissue Law can be described as having "tipped the scales in Germany from a de facto anonymity in sperm donation practices to a still fragile and not very clearly defined form of non-anonymity" (Klotz and Knecht 2012: 293).

A more far-reaching limitation of the power of the medical profession was implemented ten years later. In 2017, the Sperm Donor Register Act (Samenspenderregistergesetz; SaRegG 2017) was passed. A central national register began its work one year later. It is managed by the Federal Institute for Drugs and Medical Devices (Bundesinstitut für Arzneimittel und Medizinprodukte). ${ }^{18}$ At the same time, the Civil Code was adapted, and sperm donors can no longer become the legal fathers of

14 The practice of storing information with a notary was described to me in personal communication by Claudia Brügge, the head of the German organisation DI-Netz ("DI network"). The practice is also recounted through Zypries and Zeeb (2014).

15 Spenderkinder argues that since the 1960s, it was already accepted by legal scholars and courts that there was a right to know. In addition, the association argues that the code of medical ethics provided that documents should be kept longer if it was deemed necessary.

16 This was reported to me by several of my German interviewees who had contacted the clinics where they had been conceived. They had been told that there were no records left for treatments that took place prior to 1997.

17 In 2017, for example, a couple whose child had been conceived after 2007 only received identifying donor information after they won a lawsuit against a sperm bank (Amtsgericht Wedding 2017). In contrast, a German lawyer told me that a sperm bank had immediately released information when he contacted them on behalf of a client whose child had been conceived before 2007.

18 The register was previously managed by the German Institute for Medical Documentation and Information (Deutsches Institut für Medizinische Dokumentation und Information), whose major functional units were merged with the Federal Institute for Drugs and Medical Devices in May 2020. 
donor-conceived children, and can no longer be made liable for child support. This was theoretically possible before that but never happened. Those conceived with donor sperm after 1 July 2018 will in the future be able to request identifying information about their donor, which has to be stored for 110 years, from their sixteenth birthday. In contrast to the UK, donors cannot directly apply for information about the children conceived with their donation. However, they are informed when information about a birth resulting from treatment with their semen is registered. They can thus indirectly draw conclusions about how many children were conceived through their donations. A special feature of the German law is that prior to the child's sixteenth birthday, parents as his/her legal guardians can also receive identifying information and may request it right after the birth of their child. Once their children are 16 years old, only the children themselves can access information. No data on past treatments were included in the register, as was also the case for the HFEA register. Thus, it is not an institution from which my interviewees themselves could directly benefit, even though it was seen as positive that it would be made easier for "future generations", as my interviewee Sabrina Frey put it, to obtain information. In contrast to the UK, there is currently no sibling register, which has been criticised by donor-conceived activists (Spenderkinder 2017b) and others (Brügge and Thorn 2017).

In summary, it can be said that the regulation of gamete donation and anonymity has developed differently in the UK and Germany. In the UK, following the discussions sparked by IVF, a central donor register was created, which is managed by the authority that oversees embryo research. However, donor anonymity was only limited years later. In Germany, research that involves embryos remained banned. It was not until 2018 that a central donor register was established. In contrast to the UK, donor anonymity was limited from the outset of the register's creation. Despite these differences, one thing is nevertheless similar: in both countries, the answer to the question of what information the donor-conceived can obtain through formal infrastructures is not simple. Jeanette Edwards argues that due to the various changes in legislation and because of the various voluntary registers, "the situation in the UK of what donor-conceived people can know about their donor, and when, is uneven and complicated" (2015: 102). In Germany, the situation appears to be uneven mainly because decisions on how information should be stored and released have long been made by doctors and sperm banks, without them being supervised by an authority like the HFEA. As Maren Klotz points out in her ethnographic exploration of gamete donation in both countries, "the underregulation of sperm donation in Germany made its clinical management highly idiosyncratic" (2014: 110).

In Germany, this unevenness also applies to those who were conceived in the 1980 s or earlier. While clinics in the UK were not obliged to store information in an accessible form indefinitely before 1991 (Edwards 2015: 102), it remains contro- 
versial whether doctors in Germany were required to permanently store information, with donor-conceived activists arguing that anonymity was never legal and that doctors should not have destroyed any records. This has led to several donorconceived persons suing clinics and doctors, which is not an option for those conceived in the UK. ${ }^{19}$ However, neither my German interviewees nor my British ones are among those who have (easily enforceable) official means at their disposal to access identifying information about their donor. For this reason, many of them turn to other means to find their donor or donor siblings. Commercial DNA databases are of particular importance here and will be discussed in detail in chapter 8 .

\section{2 'Identifying' current research practices and themes}

In her analysis of the psychosocial scholarship on surrogate motherhood, anthropologist Elly Teman (2008), who has herself conducted some of the first ethnographic research on surrogacy (2010), argues that it "collectively represents a cultural text on the norms and values of Western culture and reveals how Western cultural assumptions impact scientific research" (2008: 1105). In particular, she suggests that traditional assumptions about motherhood and the uneasiness with surrogacy that these assumptions evoke have had an influence on "research goals, methods and conclusions of the scarce empirical scholarship on this topic" (ibid.). Teman (2008: 1110) quotes anthropologist Margaret Lock, who called for anthropologists to "trouble" and "monitor concepts and categories" (2001: 483) used in other disciplines as if they were "universally objective" (ibid.). I find Teman's perspective on psychosocial research enlightening, as the majority of studies on donor conception in general and donor-conceived persons in particular are psychosocial in nature as well. An analysis of the existing research that oftentimes focuses on the connection between having information and "identity formation" shows that scientific knowledge does not emerge from a vacuum. It always "comes from somewhere" (Krebbekx et al. 2017: 639). It is produced through an interplay of various factors, instead of being something that is waiting 'out there' to be discovered by researchers. Scientific practices "do not take place outside social contexts, but are shaped by it, and also shape them in return" (ibid.). In this overview I will first discuss the empirical basis of a large part of the psychosocial studies on donor conception. I will then summarise some of these studies in relation to the topics that are most frequently addressed in them. Finally, I will discuss what points of reference these studies provide for my own approach.

19 See for example a 2014 blog post from Spenderkinder (2014a) for a case that was lost and another entry from 2017 (Spenderkinder 2017a) for a case where several donor-conceived persons succeeded. 
A large part of the studies that focus on donor conception - be it parents (Freeman et al. 2009), donor-conceived persons (Jadva et al. 2009; Beeson et al. 2011; Hertz et al. 2013; Nelson et al. 2013; Slutsky et al. 2016; Persaud et al. 2017), or donors (Jadva et al. 2011; Daniels et al. 2012; Hertz et al. 2015; Nelson and Hertz 2017) - have recruited participants from an informal voluntary register called the Donor Sibling Registry (DSR), an American online platform with a worldwide membership. ${ }^{20}$ The DSR was founded by Wendy Kramer, who is listed as a co-author on the majority of publications, and her donor-conceived son. What started as a Yahoo group in 2010 with the aim of enabling networking and exchange between parents, their donorconceived children and donors, has evolved into a non-profit organisation that not only has an online-based register but also frequently collaborates with academic researchers. I argue that the involvement of institutions like the DSR in research and the mixture of scientific studies with concrete calls for actions, which marks a large part of the research, point towards a reconfigured understanding of who can contribute to scientific knowledge.

This transformation has already been explored by other anthropologists. Commenting on the lobbying work of the Donor Conception Network (DCN), ${ }^{21}$ a British interest group set up by parents who have conceived with donated gametes, which has been explored in detail by Klotz (2014), Edwards (2018: 160-162) takes up the work of Michael Gibbons, Helga Nowotny and colleagues (Gibbons et al. 1994; Nowotny et al. 2001). In their theoretical work, they explore what they perceived as a shift in the dominant mode of knowledge production. They argue that the new mode of knowledge production was "socially distributed, applicationoriented, trans-disciplinary, and subject to multiple accountabilities" (Nowotny et al. 2003: 179). In contrast, the previously dominant mode was "characterized by the hegemony of theoretical or, at any rate, experimental science" (ibid.), by disciplines that remained strictly separated, and by scientists and universities that worked outside of society. They argue that knowledge is now "generated within a context of application" (Nowotny et al. 2003: 186) and by "research communities [that] now have open frontiers - which has allowed many new kinds of 'knowledge' organizations [...] to join the research game" (Nowotny et al. 2003: 187). I suggest that organisations like the DSR have succeeded in joining "the research game". Besides, "the reconfiguration of what constitutes expertise" (Edwards 2018: 161) is also noticeable in Germany, where the organisation Spenderkinder in particular is now invited to government hearings on reproductive technologies (section 4.4).

Since the DSR is different from the formal registers I examined in my own empirical work (chapter 7), I will briefly summarise its special features. It has been 
argued that it "has perhaps the most comprehensive eligibility criteria of any service" (Crawshaw et al. 2015: 75), as it can be joined by offspring, parents, and donors as well as "family members of all parties directly affected" (ibid.), whereas the UK's sibling register can only be joined by the adult donor-conceived themselves (section 7.5). Parents can register their children at an early age with their donor's code if they want to use the DSR to network with other families. Although there is no precise information on the composition of the membership, various studies and information available on the website suggest that parents make up the majority of the membership. ${ }^{22}$ Single mothers and lesbian couples seem to be the most active in terms of connecting with families whose children were conceived with gametes from the same donor. New DSR members usually register with the code assigned to each donor, which is a common practice in the US, but not in fertility clinics and sperm banks in the UK and Germany. ${ }^{23}$ The donor codes are used to facilitate "matches" between users who have registered with the same code. It is striking that "the identification numbers that dissociated men from their gametes are being used to connect the children conceived from their gametes" (Hertz and Mattes 2011: 1135), which has been described as an "ironic twist" (ibid.). A mechanism designed to separate donors from their gametes and to sever all ties between recipients, donors and offspring is now being used to create unprecedented connections. According to its website, the DSR had almost 75,000 members in May 2021, and more than 20,000 offspring had been connected with their donor siblings and/or donor. Overall, the DSR can be said to "promote[...] the idea that it is socially enriching and satisfies natural curiosity [...] to get in touch online or even form closer relationships" (Klotz 2014: 270).

While the majority of studies conducted with DSR registrants and/or members' children consist of online-based surveys that usually contained closed and open-

22 DSR members do not have to provide any information about their family type. However, questions about, for example, marital status are usually part of research surveys. According to the website (https://donorsiblingregistry.com/our-members\#background_on_member s, last accessed May 31, 2021), it is estimated that $49 \%$ of members are single mothers by choice; $33 \%$ are LCBTQ families; and $17 \%$ are heterosexual couples (or were conceived by them).

23 While visitors can browse the register, only registered and fee-paying members can contact other members. The only DSR registrant I interviewed pointed out that the DSR might possibly have more members from the UK than one might think: a former donor I met through the voluntary register DCR mentioned that he had joined the DSR because "a lot of UK people who haven't found our register go there". Since I did not try to find interviewees via the DSR, I did not follow up on this. According to those of my interviewees who had joined the DCR, the register was indeed not very well known (section 7.6). Although it seems unlikely to me that someone interested in their donor and/or donor siblings would find the DSR but not the DCR when looking for information, I would not rule out the possibility that my interviewee was right, as the DSR is a lot more present in the media than the DCR. 
ended questions, two recent studies (Slutsky et al. 2016; Persaud et al. 2017) built their analysis upon the results of face-to-face interviews conducted with adolescents (aged 12-19) whose mothers were members of the DSR, and who had been conceived with anonymous sperm donations. In both articles, the parent-child relationship is portrayed as laying the foundation for how donor-conceived persons think and feel about the circumstances of their conception. Slutsky et al. argue that those adolescents who are "securely attached" (2016: 206) were most likely to engage in the "sometimes challenging task of exploring donor conception" (ibid.) and express curiosity in their unknown donor. They conclude that the study's findings "suggest that the valence of the parent-child relationship influences the adolescents' appraisal of their donor conception within the context of their growing sense of identity" (2016: 207). Being open with the child and within the "wider emotional context of the family" (ibid.) are portrayed as the factors that enable the donorconceived to "positively integrat[e] donor conception into a coherent sense of identity" (2016: 203). The connection between the desire to find out more and a secure identity is also central to the second article (Persaud et al. 2017), which examines adolescents' experiences of contact with donor siblings. Persaud et al. argue that their desire to meet them was motivated by the desire to learn more about the donor and themselves. They suggest that finding similarities between them and their donor siblings allowed them to develop "a better sense of their genetic background and identity" (2017: 20).

While these studies focus on openness, contact with donor siblings and the respective connection with identity, Scheib et al. (2017) explore the link between "identity formation" and temporally limited anonymity. The persons interviewed for their study were all conceived with sperm from The Sperm Bank of California (TSBC), which has offered an "Identity-Release ${ }^{\circledR}$ Program" with donors whose identifying information the donor-conceived can request at the age of 18 since 1983. The TSBC stopped offering anonymous donations altogether in 2016. Nowadays, the term "identity release" is often used for donors whose information can be "released" to their offspring, usually when they reach a certain age (see for example Graham et al. 2016 and Hertz et al. 2015). Although the term "release" has positive connotations, and is associated with freedom and development, it is also used to refer to the dangerous release of toxic substances. ${ }^{24}$ While the TSBC presents openness and identifiability as having a positive impact on individuals and families, the term "identity release" also frames donor information as something that can have profound consequences for those who request it. This is similar to the

24 See for example anthropologist Kim Fortun $(2001,2009)$ on the "Toxic Release Inventory", a publicly available database about information on the release of chemicals by industry groups and federal facilities. It was established in the US in the aftermath of the Bhopal disaster (see also section 3.5 for a discussion of environmental "right to know" debates). 
way in which HFEA texts, which do not speak of "identity-release donors", "depict accessing information as a 'big decision' with profound emotional consequences" (Gilman and Nordqvist 2018: 322; see also section 7.1).

Similar to the DSR, the TSBC has long been involved in academic research. Since 2000 , its research activities and programs are headed by research psychologist Joanna Scheib from UC Davis. She has written and co-authored numerous widely cited articles that primarily focus on the TSBC's "Identity-Release ${ }^{\circledR}$ Program", lesbian and single mothers and more recently on contact between families with children conceived with sperm from the same donor (for example Scheib et al. 2005; Goldberg and Scheib 2015; Goldberg and Scheib 2016). Those interviewed for the 2017 article were all adult offspring conceived with sperm from identity-release donors, which are referred to as "open-identity donors" in the paper (Scheib et al. 2017). About a third had already requested identifying donor information, which had first become available in 2001 when the first eligible donor-conceived person turned 18. Scheib et al. argue that those who requested identifying information "hoped for an expanded sense of their identity" (2017: 492) as part of a "process of identity formation [that] seemed important for their sense of belonging" (ibid.).

Identity, its formation and the factors that can disrupt it are also at the forefront of the studies that did not find their participants through the DSR or the TSBC. In general, there seems to be a consensus that being told late in life, in combination with not being able to access donor information, results in what psychologist Maggie Kirkman describes as "a fractured sense of identity" (2004: 15) in her qualitative narrative study of recipients, donors and donor offspring from several different countries. This also applies to one of the first studies on the experiences of donorconceived persons, which was published in 2000. Amanda Turner and Adrian Coyle found that their study participants (from the UK, USA, Canada and Australia), who were sent a semi-structured questionnaire via email and post, "expressed a need and a right to know who their donor fathers are and, if possible, to have some sort of relationship with them" (2000: 2050). None of them had a legal right to obtain identifying donor information. Turner and Coyle argue that providing them with non-identifying information is not "sufficient to meet their identity needs" (ibid.) and that not being able to know "their full genetic history posed a threat to their identity" (ibid.).

In a later study consisting of interviews of people aged 19-29, raised by lesbian parents and conceived with known donors in the US, Abbie Goldberg and Katherine Allen found that their participants tended to become more interested in their donor as they grew older (2013: 327). They argue that this is "indicative of a turning point in their identity, emerging as they were coming of age, in late adolescence or young adulthood" (ibid.). In contrast to this study, for which semistructured telephone interviews were conducted, clinical psychologist Astrid Indekeu and bioethicist Kristien Hens (2019) conducted focus group interviews with 
twelve donor-conceived persons from Belgium ( $n=11)$ and the Netherlands $(n=1)$. All were "born under a legal system of donor anonymity and an atmosphere of secrecy" (2019: 20). Those who were raised by heterosexual couples had not been told until adolescence or adulthood. Indekeu and Hens seem to both relativise and simultaneously emphasise the importance of genetic information: "How we think about genes is [...] shaped by the societal, professional and political discourse on the topic. But it is also undeniable that genes are the biological building blocks of a human being and are linked to resemblance and identity." (2019:34) In an online questionnaire-based study that was conducted with registrants of the voluntary pre-1991 register in the UK, van den Akker et al. found that donor-conceived participants had a "lowered collective identity" (2015: 119), which they describe as a "concept referring to a belief that one shares characteristics with a group of others" (ibid.). They interpret this finding as indicating that "belongingness is critical to identity" (2015: 120).

Apart from the "identity effects" of donor conception and/or anonymity, studies oftentimes address the effects of secrecy, openness and disclosure on the wellbeing, or "functioning", of entire families. This was already the case for the studies conducted by professor of sociology Robert Snowden and his colleagues (Snowden et al. 1983, 1985), who were among the first to conduct empirical research with recipient parents in the UK. ${ }^{25}$ Their interlocutors had been treated by Margaret Jackson, one of the "main protagonists of DI provision" (Blyth 2004: 226; see also Jackson 1957), with sperm from anonymous donors. Snowden and his colleagues argued that the stress caused by trying to keep the use of donated sperm and male infertility a secret aggravated the overall burden placed on couples undergoing fertility treatment (Snowden et al. 1985: 60). They believed that couples should be helped to gain a different understanding of male infertility rather than to be encouraged to keep it hidden from their child, while at the same time advocating donor anonymity. ${ }^{26}$ Their studies contributed to donor conception coming "more fully on to the public agenda" (Haimes 1998: 59) in the UK, with other non-medical professionals becoming involved in the field as well (ibid.).

25 A study similar to the ones conducted by Snowden and his colleagues was not carried out in Cermany. However, their book Artificial Reproduction (1983) was translated into Cerman by Professor of Dermatology Walter Krause (Snowden et al. 1985). The fact that a book on DI, which was back then still conceptualised as a treatment for male infertility, was translated by a dermatologist is linked to the history of andrology in Cermany. In contrast to clinics in other countries, where andrology developed as a urological sub-discipline, the majority of German andrology clinics emerged as a subfield of dermatology in the 1950s (Kampf 2013: 25).

26 Snowden argued in 1984 that "there would seem to be good reason for maintaining the anonymity of the donor" (1984: 262), as identifiability might result in "conflicting emotional ties between the family of the recipient and the family of the donor" (ibid.). 
The benefits of early disclosure in particular are addressed by Blake et al. (2010) in a study conducted as part of a longitudinal research of families created with the help of reproductive technologies in the UK. They interviewed both parents who had told their 7-year-old children that they were donor-conceived and children who already knew about the circumstances of their conception. All but one child (who had a known egg donor) had been conceived with anonymous donations. According to the authors, a great "majority of children responded to disclosure in a neutral way, or had no reaction at all" (2010: 2533). They argue, however, that those who decide to disclose should keep in mind "that disclosure is an ongoing process" (ibid.) and that children's understanding of donor conception is likely to evolve as they get older. In a follow-up study of the disclosure decisions of families in the UK, all of whom had children conceived via anonymous DI, Tabitha Freeman and Susan Golombok (2012) found that non-disclosure did not necessarily result in weaker family relationships. However, they point out that "observations of positive functioning in non-disclosed families must be weighed against the risk of accidental disclosure in later life and the potentially negative outcomes associated with this" (2012: 201). This mirrors the results of an earlier European study (Golombok et al. 2002). Freeman and Golombok also highlight the "positive functioning in disclosed families" (2012: 201) and argue that openness "does not appear to create significant difficulties in family functioning and child psychological adjustment" (2012: 202). Disclosure is thus advocated not on the grounds of a right to know, but rather on pragmatic terms that nevertheless promote a specific ideal, namely that of the harmonious family whose members do not keep secrets.

Comments about identity and the damage that anonymity and secrecy could cause to it were abundant in the interviews I conducted. My interviewees frequently mentioned that they experienced an "identity crisis" when they found out that they were donor-conceived, had started to "loose identity", and emphasised that "knowing where you come from" was essential for a child's "identity formation". While I take the theorising of my research contacts seriously, I suggest that an epistemological and analytical distance to their statements is necessary to avoid a mere replication of their descriptions. I contextualise the stories of my interviewees and make them an object of ethnographic investigation. This means that I interpret neither anonymity nor secrecy as inherently dangerous to individuals and families, and that I also interpret "identity" differently than the psychosocial studies I have presented. Their authors seem to conceive of identity as something that is primarily formed in childhood and that can be shaken by new, unexpected information about one's origins and by the impossibility of getting to know the donor. Following Strathern and her concept of "constitutive information" (1999c), I conceive of information about the circumstances of a person's conception, the use of gametes and the donor as something that constitutes identity. It is the "cul- 
tural coupling with identity" (1999c: 68) that makes information about a donor "a particular kind of knowledge" (ibid.).

It should be noted that Strathern otherwise tends to avoid the term "identity". In a recent interview with sociologist Joanna Latimer, Strathern argues that it is "one of those incredibly loaded Euro-American concepts that made its use for analytical purposes really suspect" (Strathern and Latimer 2019:490). ${ }^{27}$ She has written elsewhere (2017) about how identity was "invented": "It is to the scientific and philosophical innovations of the European seventeenth century that we owe the concept 'identity'." (2017:20) It is "applied to the self-sameness of persons quite as much as of things" (ibid.). I share Strathern's concerns, especially given the extent to which the concept is used in psychosocial studies and by my interviewees themselves, even though I do not avoid the term completely. I speak, for example, of the wish to know "the identity of the donor", whereby I mean a condition in which identifying information is not disconnected from a donor. By contrast, anonymity means that "identifying information is dis-associated from a person or simply vanishes" (Bachmann et al. 2017: 249).

This short overview of psychosocial studies also shows that there are several research gaps in terms of who is studied and what methods are employed. ${ }^{28}$ I will explain the methods I used and my research process in chapter 2. Much of the existing research on donor-conceived persons has recruited its participants through voluntary registers (DSR and TSBC), with the majority of them having been conceived in the US, where reproductive technologies are largely unregulated. There are relatively few studies that focus on Europe and donor-conceived adults instead of children, and, apart from Klotz (2016), no ethnographic explorations. ${ }^{29}$ In this

27 Strathern uses the term "Euro-American/Euro-Americans" "to summon those whose cosmologies were formed by the religious and rationalist upheavals of the seventeenth and eighteenth centuries across Northern Europe, creating present-day America in their wake" (2005: 163). Furthermore, she argues that "Euro-American influence [...] has global spread" (ibid.). It is thus not confined to Europe and North America. Strathern argues that this "hybrid [term] is preferable to the monolithic "Western" (1992: 11), although it seems that "Euro-American" is in fact often used as a substitute for "Western" (Bergmann 2014: 27). While I do use the term "Euro-American", I am aware of the fact that it can be "a hindrance when attached to particular populations and real lives" (Edwards 2008: 7) and might, similar to the term "Western", again be too monolithic. If one takes into account the law "as a site in which certain kinship understandings are crystallised" (ibid.), it becomes clear that significant differences exist between the countries where I conducted research: for example, ova donation is permitted in the UK but not in Germany.

See Canzi et al. (2019) for a systematic review of studies conducted about donor-conceived persons.

29 Drawing on ethnographic interviews conducted with two donor-conceived adults in the UK, ongoing contact with a member of Spenderkinder and a worldwide newsgroup, Klotz explored "wayward relations" (2016), which she defines as the "searches and relationships be- 
book I investigate the narratives of donor-conceived persons from countries where gamete donation and anonymity were regulated differently and with varying degrees of formal control exerted by official authorities and/or physicians. While previous research on how the donor-conceived access information and come into contact with the donor and/or donor siblings has mainly focused on voluntary and informal registers, in this book I will look at a whole range of possibilities, including formal and informal infrastructures (chapter 7) as well as "subversive uses of genetic testing" (Klotz 2016: 52) (chapter 8). I will thus explore the transformation of anonymity at the intersection of various regulations and infrastructures, while also focusing on social practices and relations. I examine not only how the donorconceived form connections with anonymous and/or identified genetic relatives but also how they form new relationships with each other.

By "[o]pening up anonymity" (Konrad 2005a: 241) and other forms of nonknowledge, instead of focusing on its consequences for "identity formation", relational and temporal practices and questions of power and politics can be investigated. Since questions of anonymity in gamete donation and its effect on "identity formation" are morally charged, the following is usually forgotten: anonymity "is able to function to both good and bad ends" (Ponesse 2013: 322, emphasis in original). Anonymity is notably "tied to a fundamental set of values associated with the European enlightenment: liberté, egalité and fraternité" (Bachmann et al. 2017: 245), as it may ensure freedom from surveillance, guard against the establishment of hierarchies by removing certain social categories from a person and enable new forms of collaboration. At the same time, it may also "promote the promulgation of hate speech" (Ponesse 2013: 321) and has the potential to "create a special sort of license to perform moral transgressions we might otherwise resist" (Ponesse 2013: 322). The multifaceted nature of anonymity and the many different ways in which anonymity can be socially productive (Bachmann et al. 2017) have been explored in various ethnographies that deal explicitly or implicitly with anonymity in a variety of contexts. A small but ethnographically rich selection of these works will be presented in the next section.

\subsection{Situating anonymity}

In my exploration of anonymity in gamete donation, I start from the assumption that anonymity is always something that is situated (Bachmann et al. 2017: 243). In this section, I will discuss a couple of ethnographies that have explored situated 
anonymity in a variety of different fields, namely Monica Konrad's work on ova donation (2005a), Jacob Copeman's exploration of blood donation (2009), the work of Lesley Sharp (2006) and Margaret Lock (2002) on organ donation, several explorations of the lesser-known practice of breast milk donation (notably Cevese 2015), and Catarina Frois's (2009) inquiry into self-help groups. Of course, this small selection of topics does not cover all fields in which anonymity has been explored. It leaves out, for example, studies that have looked at anonymity in the virtual world. Gabriella Coleman's work on the activist online network Anonymous (Coleman 2014) is of particular importance here. I have chosen to focus on ethnographies of the donation of ova, blood, organs and breast milk in order to show how differently the importance of knowledge, and thus the meaning of anonymity, is negotiated in relation to the origin of bodily substances and fluids. I have included the work of Frois (2009), as her study of self-help groups is one of the few that deals with anonymity in physical interactions, illustrating that anonymity does not have to equal facelessness.

An ethnography that is arguably path-breaking not only for the study of anonymity but also for ethnographies of gamete donation is Konrad's Nameless Relations (2005a; see also Baumann 2017 for a more detailed review). Konrad conducted ethnographic research on anonymous ova donation in the mid-1990s in three English fertility clinics, interviewing both donors and recipients who could not receive identifying information about each other. Since the women remain mutually anonymous, recipients cannot make reciprocal return gifts, and the "principle of balance" (2005a: 41) is thus blocked. However, Konrad shows that anonymity can be explored as a form of sociality: despite never meeting up in person, donors and recipients establish "relations of non-relations" (2005a: 49). While they cannot make reciprocal counter-returns, Konrad suggests that "in anonymous sociality relations of non-relations are mediated by the (non) knowledge of transilience" (2005a: 242). "Transilience" describes an abrupt change or leap from one thing or state to another. Konrad argues that "the substance of transilient relations is made from the anticipation of a future, as yet unknown, kinship whose processual activation sometimes may span several years" (2005a: 49). Since donors and recipients cannot know each other, transilient relations are imaginary and marked by "a sense of intimacy at a distance" (2005a: 98). Konrad suggests that they are 'killed off' by actual physical encounters (2005a: 214). While a donor cannot know neither the identity of the ova recipient, nor the outcome of her donation, she can compensate a lack of knowledge "by the continuous work of transilience that keeps ties alive as imagined relations" (2005a: 115). I will return to Konrad and her idea of "active not-knowing" (2005a: 170) in section 5.4.

A work that picks up and expands Konrad's ideas is Copeman's ethnography Veins of Devotion (2009), in which he investigates blood donation in India. Since public campaigns aimed at raising awareness for voluntary blood donation have not 
yet been very successful, religious movements have become important providers of voluntary blood donations throughout the country (2009: 3). Donations at "recordbreaking 'mass' or 'mega' blood donation camps" (2009: 105) are voluntary, unremunerated and anonymous and therefore differ considerably from a system that is based on paid donations and replacement donations. ${ }^{30}$ Copeman's work on donation camps staged by devotional orders, which attract thousands of people, shows "that anonymity need not be synonymous with alienation and passivity but may rather provide a kind of imaginative canvas for novel ideational maneuvers" (2009: 10). In particular, Copeman argues that the ideology of national integration is "recreated and reasserted" (2009: 150) through large-scale camps where organisers often attempt to gather people from diverse backgrounds (2009: 158-159). Taking up Konrad's concept of transilience, he suggests that blood donation camps can be seen as "the basis of a "national transilience": the enactment of threadlike imaginative extensions across diverse plurality as the folding of different constituencies into a single social field" (2009: 165). He gives the example of a Muslim donor who imagines his donation to transgress the boundaries of religion and caste and quotes him as saying that his donation is "for the integration of people" (ibid.). Copeman's work thus shows, like Konrad's study, that "anonymity can open up new spaces of ideation and relational reckoning" (2009: 11). Veins of Devotion and Nameless Relations both demonstrate that anonymity is not asocial, and that it can in fact be a form of sociality.

In organ donation, anonymity has long been regarded as something that protects both donor kin and recipient: on the one hand, it is perceived as something that enables the relatives of the deceased donor to mourn peacefully, without being disturbed by recipients who might try to contact them. On the other hand, it is seen as a mechanism that ensures that recipients do not identify themselves with donors and feel even more guilt than they already do after being given the chance to live on through someone else's death (Sharp 2006: 106). It is striking that, as I have shown in section 1.1, anonymity in gamete donation was also previously seen as a protective mechanism before a far-reaching change occurred. A transformation can also be observed in organ donation. In Strange Harvest, her ethnographic study of organ donation in the US, Sharp argues that there have been "radical shifts in the ways that cadaveric organ donors are described and, ultimately, imagined in the transplant arena" (2006: 105). One of these shifts is "the recent challenge mounted by numerous donor kin against the assumption that the anonymity of donors is crucial to organ transfer's success" (2006: 106). Since the idea that "transplanted organs can retain the life essence of their donors" (2006: 4) is central for the way

30 A "replacement donor" is a friend or relative of the recipient who donates blood in order to replace the blood used in a treatment, ensuring that the clinic or bank has a consistent supply of stored blood. 
in which donations are understood in the US, not being able to know who received the organs of a loved one can be experienced as detrimental.

While encounters between donor kin and recipients used to mainly happen by chance, Sharp argues there has been "a dramatic shift from renegade acts of personal contact to more carefully, and professionally, orchestrated encounters" (2006: 180). Organ procurement agencies and transplant units have started to rethink and reshape their policies on anonymity (2006: 106). As part of this transformation, communication between the different parties has become bureaucratised. Special communication coordinators mediate the exchange of anonymous letters, which they might edit before passing them on (2006: 179). While protocols and guidelines make a meeting more likely, they also mean that the final decision to make contact lies with coordinators who decide "on a case-by-case basis whether personal encounters should occur" (ibid.). Sharp does not explain how coordinators proceed with the editing of the letters and, above all, what information they classify as identifying and thus decide to edit out. An editing process is also carried out at the HFEA, as officers have to review donor information before sending it to those applicants who are not entitled to identifying details. As I will show in my discussion of the HFEA's "redaction process" (section 7.2), the decision as to whether information is considered to be identifying or not is determined by a variety of factors and practices.

Another ethnographic account of organ donation that addresses the question of anonymity is Lock's monograph Twice Dead (2002). Lock argues that ideas about a donor 'living on' in the recipient individualise donation, which "encourage[s] anthropomorphization and fantasies about personality changes" (2002: 372). Donor kin worry about the whereabouts of the donated organ and the identity of the donor, having no chance "to come to terms with the finality of death" (ibid.). Lock suggests that this increases resistance to donation in North America. Her ethnographic research in Japan opens up a particularly interesting perspective on anonymity, as she observed a similar kind of resistance in the Asian country. The reluctance to donate, however, had other reasons. In contrast to American donor kin, "Japanese families do not fantasize about individual transcendence of death but rather worry whether recipients will treat their relatives' organs with due respect." (Ibid.) However, Lock found that many Japanese would still prefer a donation from an anonymous donor, who has consented to the donation, to a living donor transplantation from a known relative (2002: 334). Lock argues that in a society such as Japan that is "bonded through networks of reciprocity and exchange" (ibid.), the "burden of reciprocity" (2002: 335) that comes with a living donation can be unbearable. Receiving an organ from an anonymous donor is ascribed a protective function, as anonymity makes reciprocal exchanges impossible from the outset. It is thus not a matter of fending off future difficulties that may 
arise from contact with donor kin, which is a main reason why gamete donors are anonymised, but of not burdening existing relationships.

Anonymity can also have a protective function for self-help groups where it may be crucial for creating equal relationships between members. In The Anonymous Society (Frois 2009), an ethnographic study of Alcoholics Anonymous, Narcotics Anonymous and Families Anonymous in Portugal, Frois argues that in these groups, anonymity is "used to minimize and level out [social and cultural] differences" (2009: 158). While it might seem strange to speak of anonymity in a situation where people meet face-to-face in an offline environment, Frois found that it is anonymity that the members speak of and it is in fact anonymity that they want to preserve" (2009: 174). According to Frois, anonymity in self-help groups has inside and outside dimensions to it (2009: 156): on the one hand, anonymity is important for the relationships within the group, as participants do not have to reveal anything about themselves apart from their condition or problem. On the other hand, it is a protection from the outside world that might stigmatise those who attend (2009: 161-163). Frois concludes that anonymity constitutes "a method for managing revelation and concealment" (2009: 174). These two processes "imply a tension which is fundamental in member's lives: revealing or hiding where, to whom and why" (2009: 175, emphases in original).

Frois found that only few people allowed the inside and outside of a group to overlap (2009: 176), although she observed that members would sometimes "establish preferential relationships with a few others, to whom they reveal information omitted so far" (2009: 164). Frois does not go into detail about situations where it may be important or desirable for members to reveal their identity, arguably because she believes that anonymity breaches, despite being common, "cannot be generalized" (2009: 165). The question of with whom one should share information was repeatedly addressed by the persons I interviewed. They frequently asked themselves whether to tell friends and relatives about the circumstances of their conception (sections 6.2-6.4). It was thus not about sharing information that would reveal the identity of the person in question, whose name their friends and relatives knew; the information would however identify them as donor-conceived. It should be noted that anonymity could be "a method for managing revelation and concealment" (2009: 174) in my field as well. Some of my interviewees would choose to appear in the media anonymously (section 4.2) or worry a great deal about how I anonymised them (see for example Timothy Parsons in section 6.1), as they did not want others to find out they were donor-conceived.

While remaining anonymous was considered necessary by my interviewees in certain situations, it was clear to the majority of them that the anonymity of gamete donors had to be rejected. If you do not know the donor's identity, they reasoned, you do not know where you come from. In their way of conceptualising kinship, knowing the identity of the donor is important because the donated gametes have 
created an indissoluble link between them and their donor. As Strathern points out, "it is not the case worldwide that the foundation of relationships is held to rest in [...] biogenetic facts" (1995: 349). There are many different ways of creating and 'doing kinship', which has implications for the type of knowledge that is considered important. Depending on from where kin ties originate, it may not (or at least not only) be knowledge about those involved in one's biogenetic conception that is important. This becomes evident in the practice of human breast milk donation and banking and the way the anonymised nature of breast milk is, at least by some, problematised. Similar to banks working with donated blood, human milk banks are "dedicated to the collection, processing and distribution of a disembodied human fluid as a medical therapeutic" (Swanson 2014: 165). Donated milk becomes "anonymous, movable, mixable, and, above all, it is totally detached from the provider" (Cevese 2015: 102), before being used to feed premature babies whose mothers do not yet have their own milk (Carroll 2015: 173).

In her ethnographic study of milk banking in an Italian neonatal intensive care unit, Rosella Cevese (2015) found that immigrant Moroccan women were oftentimes reluctant to donate milk or accept donated milk for their children. Cevese argues that the practice of milk banking can be said to "challenge[...] the rules of milk kinship" (2015: 108). Milk kinship can be described "as a strategy of managing social relations by limiting or creating milk ties" (2015: 107). It is a kinship relation created through breastfeeding that is acknowledged by Islamic law as a form of kinship (Altorki 1980). Milk kinship remains socially important in the Middle East despite the practice of shared breastfeeding having declined (Clarke 2007). It turns a woman who breastfeeds a child she has not birthed into his/her "milk mother", the children into the woman's "milk sons" or "milk daughters", and those who have been nursed from the same woman into "milk siblings" (Parkes 2005). Milk kinship is something that is "not created by chance, but it is managed by important social rules" (Cevese 2015: 103-104), which is why not being able to trace the origins or whereabouts of breast milk may be perceived as problematic. Cevese cites a young mother, who had chosen not to donate her surplus milk: "I have to know the baby who would suck my milk, because he would become my "milk son" and [her daughter's] "milk brother." Who knows if one day in the future they will get married...!" (2015: 100) ${ }^{31}$ Cevese found that Italian women, despite "consider[ing] breastmilk

31 Whereas donating and procuring milk through banks is a regulated process, in the case of informal milk sharing, recipients and donors tend to make their decisions about what rules to follow on a case-by-case basis (Falls 2017: 58). In her ethnographic study White Gold, anthropologist Susan Falls (2017) highlights that a new way of organising informal milk sharing has emerged. Parents are increasingly connecting with each other via online platforms (2017: 54). Falls found that the kind of donor information recipients wanted to receive and the type of connection they wanted to form with a donor did vary. While some parents used screening forms provided by some platforms, others relied on their personal impression and on 
as a precious and nourishing substance" (2015: 104), did not share these concerns and were not worried about the identity of a milk donor and recipient. For them, breast milk was not a substance that creates kinship ties.

In this book I take up some of the themes and questions raised in the works discussed in this section. Inspired by Konrad (2005a) and Copeman (2009), I examine imaginations and imaginary relations in the context of anonymous gamete donation. Like Sharp's study (2006), my research deals with an area in which far-reaching transformations have occurred in relation to anonymity. A particular strength of my empirical material and the added value it brings to ethnographic research on anonymity is, I suggest, the fact that it opens up a very specific temporal perspective. In the case of my interviewees, all of whom were adults who had been conceived with anonymous donations, anonymity had already 'come into play' nearly two or more decades ago. In the years since their parents had undergone treatment, the conditions for donor anonymity have changed radically. This change has less to do with formerly private information about donors being publicly accessible, and more with new ways of linking information becoming available. For the most part, the parents had not intended to tell their children about the donation at all. According to my interviewees, many had been advised by doctors to keep the anonymous donation a secret. Thus, many of the phenomena I discuss in this book are unintended developments. If everything had gone the way it was often planned at the time of treatment and conception, the people I interviewed would not know about the anonymous nature of their conception. Even if they are the desired result of the treatment, they are still an unintended development in terms of the knowledge they have.

The transformation of anonymity in gamete donation has various dimensions to it and is influenced by various factors, some of which have been taken up by the works presented in this section. Of central importance in my research are infrastructures. They are, I suggest, also central to Copeman's work on blood donation (2009), although he does not use the term when analysing donation camps. Important infrastructures in my field of research are not only formal and voluntary donor and sibling registers but also commercial DNA databases. Commenting on some of the early anthropological studies on infrastructures, which highlighted "that infrastructure is a fundamentally relational concept" (Star and Ruhleder 1996: 113; see also Star 1999: 380), Sandra Calkins notes that the term has been applied to variety of entities: "Whatever arrangement of technologies, procedures, and people

inquiring the donor's medical information (2017: 59); and while some parents chose to have frozen milk shipped to them, others decided to only collect the milk in face-to-face meetings to form a better impression of the donors (2017: 62). Personal contact could be completely avoided when a third party such as a doula organised the donation (2017: 59). However, this does not seem to be a common variant, or at least is not described in detail by Falls. 
was solid enough to facilitate a set of organized practices was called infrastructure in relation to that very practice." (2016: 178) In her study of gold mining in Sudan, Calkins uses the term "infrastructuring" to attend to "the always incomplete process of making infrastructure and the continuous work at integrating, cutting, and maintaining relations between heterogeneous elements" (2016: 188). The shift in focus from infrastructure to infrastructuring can be described as "an analytical measure that shifts attention from structure to process" (Baker et al. 2018). I use the term in chapter 8 when examining the ways in which the donor-conceived use online genetic databases. Instead of postulating the "end of anonymity", I argue that a complex process of infrastructuring information, which involves these technologies, changes what can be known and by whom.

The question of how anonymity and the release of information is regulated is, for example, explored by Sharp (2006) who found that contact between organ recipients and donor kin is increasingly subject to bureaucratic procedures. The question of regulation is particularly important in my field of research where, unlike in other fields, claims to a "right to know" are formulated by specific groups. Konrad's (2005a) ethnographic research on ova donation took place at a time when donations in the UK were still permanently anonymous by law. She already noted back then that many of those who advocate a fundamental right to know of the donor-conceived "have turned to legal instruments in an attempt to press their case" (2005a: 36). Since special significance is ascribed to knowledge about genetic origins, discussions about anonymity in gamete donation are morally and emotionally charged. This is particularly evident in the discussions about a "human right to know" (section 3.1). The demands that the donor-conceived make are often demands that concern the regulation of information. They demand that the donor's identity be known and claim that the state has a duty to ensure and, if necessary, enforce disclosure by including information in official documents (section 3.6). This book also examines the networks that the donor-conceived form in order to enforce their claims and the role the Internet plays in this (sections 4.3 and 4.4)

\subsection{Knowing kinship}

While there are relatively few ethnographies that explicitly deal with anonymity, the situation is different when it comes to relationships: "If there is one story that anthropology has always told well, it is the story of relationships." (Klotz 2016: 45) This seems to be particularly true for kinship. However, the nature of the story has changed significantly over time. While in the past kinship was seen as a solid structure, today it seems almost banal among anthropologists to say that it is something that is done, and that doing kinship should be the focus of attention. I thus draw on the scholarly tradition of the so-called "new kinship studies" (e.g. Carsten 2004; 
Edwards 2000; Franklin 1997; Strathern 1992, 2005; Weston 1991) that have explored how kinship is done in a particular setting. ${ }^{32}$ Central to this body of work is the recognition that procreation through heterosexual reproduction is not the only way in which kin relations can be made, which is also illustrated by the work on milk kinship I mentioned in the previous section. Knowledge of the alleged "facts of life" is not as important everywhere as it is in the countries where I have conducted research. However, it certainly is "foundational to personal identity" (Strathern 1999c: 68) for the people included in this study. Since kinship knowledge "forms ('constitutes') what [people] know about themselves" (ibid.), it cannot be rejected once it has been discovered, even if it is considered irrelevant or unpleasant. Its "cultural coupling with identity" (ibid.), for which Strathern coined the term "constitutive information" (1999c), has an immediate social effect (1999c: 77). It is always more than knowledge about relationships: "knowing something about one's kin is also knowing something about yourself" (ibid.).

For people who discover that they were conceived with donated gametes, the social relationship with the woman or man who raised them, and to whom they are not genetically related, does not necessarily have to change. They might still see them as a family member and call them their "mother" or "father", which was the case for the majority of my interviewees (section 6.4). They might also choose not to pursue an active social relationship with their donor. This goes to show that EuroAmerican kinship "cannot be confined or delimited by the scientific facts about conception or birth" (Edwards 2015: 106). ${ }^{33}$ It is also "forged over time" (ibid.). Nevertheless, the donor-conceived cannot maintain that they are genetically related to their parent (although this might of course be what they tell others whom they do not want to know). While finding out that they are donor-conceived might not necessarily lead to a breakdown of their social relationships, it does constitute what they know about themselves.

As Klotz points out, "there actually has been little empirical engagement with the concept of kinship-knowledge as constitutive information" (2014: 53). Apart from her own work, which I will introduce shortly, the concept has been discussed mainly by Janet Carsten (2007). In this book I will repeatedly refer to some of her research on adoption reunions, in which she does actually not yet use the concept (2000b, 2004). Drawing on her own previous work and on other ethnographic research of not only adoption but also prenatal testing and ova donation, Carsten examines "what people do with the information they acquire, and the different ways

32 Two edited volumes that have shaped my approach to the topic are Relative Values: Reconfiguring Kinship Studies (Franklin and McKinnon 2001) and Cultures of Relatedness: New Approaches to the Study of Kinship (Carsten 2000a).

33 The way in which "[k]inship is also forged over time" (Edwards 2015: 106) has for example been examined in anthropological studies of adoption (e.g. Howell 2006). 
in which they may deploy it" (2007: 405, emphasis in original). While Strathern focused her analysis on reproductive technologies, Carsten argues that there are multiple examples in the literature that illustrate her idea about kinship knowledge being constitutive of identity (2007: 407-408). Based on her own research on adoption, Carsten also points out that "acquiring information about origins" (2007: 416) can be a means "to reassert agency over past events" (ibid.). Constitutive information is thus not only about personal identity but also about agency. Lastly, Carsten found that despite not being able to outright refuse information, adoptees and others can nevertheless manage information by attempting to control "the destabilizing force of new kinship information" (2007: 421), for example by not telling their own children that they had met their birth parents. Such tendencies can also be observed among the donor-conceived persons I interviewed. It was striking that when thinking about who should be told, the right to know and norms of honesty and transparency were less important than considerations of care and the desire to avoid "kinship trouble" (chapter 6).

Klotz herself focuses on such "tactics of active management" (2014: 54) in her study of British and German families that chose to tell their donor-conceived children about the circumstances of their conception. She borrows a term from management and organisational theory, namely "knowledge-management", "to refer to these active processes in families, clinics, regulation, and interest group activism" (ibid.). The term connotes not only practices but also the involvement of "material and immaterial information infrastructures" (2014:55). Instead of pointing towards "a growing currency to genetics/genomics within different social arenas" (2014: 338), her findings are indicative of "the rise of transparency as moral imperative for various forms of information-sharing and as a framework to manage problems" (2014: 340). When transparency becomes "infused with an explicit moral judgment" (2014: 341), non-disclosure becomes equated with lying (2014: 213-217), and "inequalities in knowledge distribution" (2014: 218) are viewed as "something to be avoided" (ibid.). She found that parents managed kinship knowledge through a variety of strategies, for example by advocating a certain terminology and not referring to the donor as "biological father" and using special 'disclosure books' to tell their child early on (see also section 6.4). She also observed a "subversion of official regimes of knowledge-management" (2014: 349) through voluntary registers and DNA testing. This aspect of knowledge-management in particular is taken up in this book and especially in my analysis of genetic databases (chapter 8), which have grown considerably in terms of their membership base since Klotz conducted her fieldwork.

Commenting on UK debates on disclosure, Edwards notes that calls for openness promote a particular vision of family life, namely "a family that flourishes on open communication and honesty between parents and their children and one where relations of equal and individual rights rather than authority or hierarchy 
are preferred" (2018: 157). She argues that this "push to more openness and transparency in donor conception is informed less by the practices that go on within actual families, [...] and more by a particular politics and value in specific forms of family relationships" (2018: 167). The kinship relations that are valued are those that are completely "see-through" (2018). This was also the case for the people I interviewed. While some believed that "real families" were only those whose members were genetically related to each other (section 4.1), the vast majority of people emphasised that what mattered most was openness and honesty (section 4.2). "Good families" were those that were "see-through". According to Edwards, calls for openness that denigrate anything other than early and full disclosure are "of a piece with calls for more transparency and openness in many spheres of personal and political life in the first decades of the twenty-first century" (2018: 166). Parents who have conceived with donated gametes and seek to keep the treatment secret because they fear being stigmatised by their community are considered not only improper parents but also improper citizens. Edwards concludes that the ideology of the transparent family "allow[s] some rather than others to belong unproblematically to the state in which they reside" (2018: 169). She argues that anthropologists "need to remain alert as to what and who gets invisibilized" (ibid.) when there is "a moral imperative to disclose" (2018: 167).

The testimonies of the donor-conceived carry weight in discussions on disclosure and donation. Drawing on her experience as a member of the Nuffield Council on Bioethics working party on disclosure and donor conception, and its consultation exercise where donor-conceived persons testified, ${ }^{34}$ Edwards points out that

"The firsthand account of the "directly involved" legitimates emergent authority with authenticity. In the case of the debate on disclosure and donor conception, the strong and compelling voice of donor-conceived adults backed by supporters, including social workers and counselors, is powerful. It is not easy to gainsay an account of the personal experience of hurt and betrayal - put powerfully and idiomatically to the working party as a "life screwed up" - caused through not being told something that is then generalized as a deliberate conspiracy to withhold

34 In 2012, the Nuffield Council on Bioethics, a UK-based independent charitable body, commissioned a report on information sharing in donor conception: "At stake was the question of whether donor-conceived offspring should always be told the means of their conception so they can know, at some point, the identity of their donor." (Edwards 2018: 156) In preparation for its report, which was published in 2013, the Council launched a consultation exercise and conducted several "factfinding sessions" with representatives from various organisations as well as individuals, such as donor-conceived persons, recipient parents, donors, medical professionals, and researchers. In addition, the Council also issued a "call for evidence" that allowed organisations and members of the public to submit replies. 
information. It is relatively easier to condone the idea that "the establishment" conspires to keep its workings hidden." (Edwards 2018: 161)

An example for the authority ascribed to the donor-conceived and their 'authentic' stories can be found in an article authored by family law commentator and practitioner Andrew Bainham (2008) in which he argues for a reform of birth registration. ${ }^{35}$ Bainham refers to the testimonies of two donor-conceived persons who presented to the committee on the Human Tissue and Embryos Draft Bill, which eventually resulted in the 2008 amendments to the HFE Act. Both of them argued that the state had to protect and enforce their right to know. Bainham maintains that these views should be taken "extremely seriously. They are not based on academic theorising but on direct personal experience." (2008: 465) The question arises as to what this means for anthropologists (Edwards 2018: 161). Apart from pointing out "that there are different ways in which flourishing kin relations are forged" (ibid.), researchers might also argue "that it is not axiomatic that a healthy "selfidentity" correlates with knowing one's biological parents" (ibid.). However, I suspect that Edwards is right in assuming that such arguments might lead to anthropologists being "accused of complicity: complicity in allowing a parlous state of affairs to continue" (ibid.).

Apart from Strathern's notion of constitutive information, I also draw on her 1995 essay "Displacing Knowledge: Technology and the Consequences for Kinship" and the predictions or "extrapolations" she formulates. ${ }^{36}$ Fundamental to her analysis is the assumption that procreation and reproduction are different. She describes reproduction as the process that "refers both to the biological aspects of producing new children and to the perpetuation of aspects of personal identity over time" (1995: 347). She notes elsewhere that "a reproduction always shows its relationship to the original: the old entity is present in new form" (1999b: 209). In contrast, "Procreation refers to the generative moment, to the act of beget-ting [...] Offspring may be implied, but nothing about their similarity to the original." (1999b: 210) Strathern argues that in contrast to procreation and "the process of conception and birth" (1995: 347), "reproduction cannot occur in the absence of a certain kind of knowledge about the identity of others" (1995: 354). An anonymous donor might thus be involved in the procreation of a child, but not in his/her reproduction (ibid.).

35 The connection between authenticity and authority is laid down in the etymological origins of the term. It derives from the Greek word "authentes", which can mean both "one who acts with authority" and "made by one's own hand" (Bendix 1997: 14). 
Strathern's first extrapolation concerns the displacement of the family. ${ }^{37}$ Previously, "both the mother and the father were responsible for the production and reproduction of the child" (Cadoret 2008: 82). While "procreation was once a symbol of reproductive continuity" (Strathern 1995:354), the creation and reproduction of a child no longer coincide when the child is conceived with donated gametes. Strathern notes that while previously it was caretaking roles that could be assumed by several persons, reproductive technologies have resulted in the dispersion of something else: "In some of the current facilities offered by assisted conception, it is the range of those involved in procreation itself that has become dispersed." (1995: 352) There is a plethora of procreators that include those who need assistance to conceive, and those who offer assistance. While it is the couple that reproduces the child, "the kinship is dispersed" (ibid.).

Strathern argues that apart from the dispersion of kinship and its separation from the family, assisted reproductive technologies also lead to the displacement of reproduction, with identity becoming part of the procreative instead of reproductive process (1995: 360). She suggests that the more knowledge people have of "the complexity of genetic makeup" (1995: 356) and "of the likelihood of disorders being transmitted and the more accurate the tracing of genetic components, the less necessary it becomes to know the identity of the parent (1995: 356-357; see also Strathern 1992: 178). Strathern argues that while dispersed conception leads to dispersed kinship, the separation of reproduction from procreation creates a paradoxical situation: “more' kinship does not necessarily lead to 'more' relatives" (1995: 353).

While Strathern's prediction about the dispersion of kinship seems immediately plausible, the second extrapolation is somewhat puzzling at first: it seems that donor-conceived persons are very keen to know the identity of the donor after all. This applies at least to the majority of my interviewees. ${ }^{38}$ It should be noted that the desire to have a complete medical history seemed to play a minor role in the search for a donor for most of the people I have talked to (section 6.4), although I have no evidence to suggest that this has anything to do with people being able to directly 'access' their genome. However, the growing popularity of "ethnicity estimates" offered by commercial DNA databases, which promise to show registrants where they "really come from" (section 8.1), might be seen as confirming Strathern's argument: "Questions that the individual person once asked of him- or herself

37 It is important to note that Strathern does not argue that the (nuclear) family would disappear, but "that there is more to kinship than family life" (1995: 351).

38 See section 7.2 for a discussion of why it is difficult, if not impossible, to make precise statements about how large the proportion of those who want to know more really is. 
about origin and links need no longer be asked of kinship when they can be asked of the individual's genome." (Strathern 1992: 178) ${ }^{39}$

Strathern herself does actually note that "in personal and social terms it may matter considerably to individuals to know who their genetic parents are" (1995: 356). This is what Victoria Grace and Ken Daniels (2007) argue in their study of New Zealand parents that conceived with DI. They claim that Strathern's predictive account is problematic because "it is frequently the case that offspring who know that half their genes come from an unknown donor in fact do want to find out about this inheritance" (2007: 707). Grace and Daniels conclude that the separation of reproduction and procreation is not that definite and suggest that "procreation will always contain the seeds of social relatedness" (2007: 708). However, I suggest that their criticism falls short, as it fails to take into account an important part of Strathern's argument:

"[...] while the procreative act is constitutive of kinship in a biogenetic sense, making that knowledge explicit makes more not less evident the fact that the social relationship is contingent. [...] Arguments about individuals' right to know based on their rights to knowledge about themselves are arguments for knowing about the individual rather than about the kinsperson. So while kinship in Euro-American thinking may be predicated on the facts of life, learning more about the facts of life will not, these days, necessarily tell us more about kinship." (Strathern 1995: 360)

More explicit biogenetic knowledge does not contribute to "knowledge about persons as kin" (Carsten 2007: 411), but to "knowledge about individual personhood" (ibid.). This, I suggest, is particularly evident in discussions about the right of the donor-conceived to know about themselves (chapter 3). The fact that a right to know is often formulated today does not refute but rather confirms Strathern's prediction about the separation of reproduction and procreation.

While knowledge about biogenetic relationships is constitutive, it does not necessarily have to be socially activated. As Strathern points out,

39 In addition, 23andMe and other companies also offer genetic health tests (see also the introduction of chapter 6 for a discussion of genetic "right to know" debates). The popularity of such tests seems to support Strathern's argument, although it should be noted that none of the people I interviewed seemed to be very interested in genetic health tests. Tamara Haste, who had signed up with 23andMe to find her donor, told me that she had actually decided against the optional genetic health test that the company offers because her donor was still anonymous: "I thought if I do find out there's something terrible, it's not like I have any reference point, I'd just be lost knowing this information, so I clicked that I didn't want to know." Tamara mentioned that she might have decided differently "if he was around". 
Euro-American kinship always made it possible for one to be related without activating the relationship. [...] When a kin relationship is activated, it is of course acted upon either because what was already known provides the basis for social interaction (as in the way kin select those they keep up with) or else because what was not before known becomes so (and the person with the knowledge has to act on it in some way, even if only to resolve not to do anything more with the knowledge)." (1995: 354)

For my research project I mainly interviewed people who only found out about the circumstances of their conception in adulthood. They activated kinship knowledge because something that had not been known before had become known. The activation of knowledge is particularly evident in the searches for donor siblings. While one might argue that these relatives exist regardless of whether they are discovered or not, searching for siblings that have been conceived with gametes from the same donor "is geared towards igniting a spark that would otherwise lay dormant, inactive and non-sociable" (Edwards 2015: 110). I argue that the donor-conceived activate knowledge about the circumstances of their dispersed conception through a variety of factors. While they might be said to exist regardless of whether or not they know, or care, about their donor-conceived origins, it is through the activation of knowledge that they become donor-conceived. The ways in which people activate kinship knowledge and become donor-conceived will be explored in the empirically oriented chapters $(3-8)$. 